\title{
Performance Analysis of Different Techniques for Low Torque Ripple PMSM Drive using DTC
}

\author{
${ }^{1}$ Rakesh Shriwastava, ${ }^{2}$ Mohan Thakre, ${ }^{3}$ Nandkumar Wagh \\ ${ }^{1}$ Electrical Engineering Department, MCOE\&RC, Nashik (M.S.) -India \\ ${ }^{2}$ Electrical Engineering Department, KKWIEE\&R, Nashik (M.S.)-India \\ ${ }^{3}$ Electrical Engineering Department, VPKBIET, Baramati (M.S.)-India
}

\begin{abstract}
Permanent Magnet Synchronous Motors (PMSM) have demonstrated their usability in automotive and other files in the recent years. A low torque ripple PMSM drive proves to be suitable for power steering and hybrid vehicle applications. This paper presents analysis of two different techniques for low torque ripple PMSM drive using DTC and performs a comparative analysis of the ripples. The complete PMSM drives are modeled using MatLab Simulink environment where different blocks are interconnected to form the complete test setup. Input torque is applied to check the parameters of the drive including the ripples. Analysis shows that the technique Dual Inverter gives $6.442 \%$ of ripples whereas the SVPWM technique affects the output in terms of ripples by $0.9762 \%$. The theoretical analyses and simulation results indicates that SVPWM technique can reduce the flux linkage and torque ripple in a large extent and have a better dynamic and static performance as compare to dual inverter technique.
\end{abstract}

\section{Keywords- PMSM, DTC, SVPWM, Dual Inverter.}

\section{INTRODUCTION}

Permanent magnet synchronous motors (PMSM) are widely used in high-performance drives such as industrial robots and machine tools for their advantages on high power density, high-torque, free maintenance and so on. In recent years, the magnetic and thermal capabilities of the PM have been considerably increased by employing the high-coercive PM materials. In last few years, permanent magnet synchronous motor (PMSM) consequently is acquired in more and more far-ranging application, because of its properties such as small volume, light weight, high efficiency, small inertia, rotor without heat problem, etc.[1,2]. Space vector pulse width modulation DTC is a technique to reduce the ripples of the electromagnetic torque and flux linkage. Direct Torque Control (DTC) is a new control method after vector control. It abandons decoupling thought of vector control, and uses the stator flux linkage directly to control the flux linkage and the torque of motor. Thus, the dynamic response of the System is very fast [3]. The DTC control strategy is applied for PMSM in order to improve the torque characteristics of the motor, which currently has caused the extensive attention of people. The traditional DTC usually adopts bang-bang control Strategy to implement. But this control strategy cannot meet the system requirements both of torque and flux linkage at the same time, which leads to large fluctuations of flux linkage and torque generated by system and leads to the problem of pulse current and switches noise caused by higher switching frequency changes. The electrical machine that converts electrical energy into mechanical energy, and vice versa, is the workhorse in a drive system. Drive systems are widely used in applications such as fibers spinning mills, rolling mills, MAGLEV - linear synchronous motor propulsion, aircraft engines, paper and textile mills, electric vehicle and subway transportation, home appliances, wind generation systems, servos and robotics, computer peripherals, steel and cement mills, ship propulsion, etc. A machine is a complex structure electrically, mechanically, and thermally. Although machines were introduced more than one hundred years ago, the research and development $(\mathrm{R} \& \mathrm{D})$ in this area appears to be never-ending. However, the evolution of machines has been slow compared to that of power semiconductor devices and power electronic converters. An engineer designing a high-performance drive system must have the knowledge about machine performance, the dynamic model, and parameter variations. Industrial drive applications are generally classified into constant-speed and variable-speed drives. Traditionally, ac machines with a constant frequency sinusoidal power supply have been used in constant-speed applications, whereas dc machines were preferred for variable-speed drives. Dc machines have the disadvantages of higher cost, higher rotor inertia, and maintenance problems with commutator and brushes. Commutator and brushes, in addition, limit the machine speed and peak current, cause EMI problems, and do not permit a machine to operate in dirty and explosive environments. However, dc machine drive converters and controls are simple, and the machine torque response is very fast.

The vast array of synchronous motor configuration in the medium and low power ranges can generally be classified into two groups: Conventional \& Brushless. PM motors fall into the latter group. PM synchronous motors generally have the same operating and performance characteristics as synchronous motor in general operation at synchronous speed. A single or polyphase source of alternating current supplying the armature windings. If the operation of the PMSM at synchronous speed is done above the power limit this gives unstable performance, reversible power flow. A PMSM can have a configuration almost identical to that of the conventional synchronous motor with the absence of slip rings and a field winding. The absence of course, is responsible for the 
one major difference between PMSM and a conventional synchronous motor: lack of power factor or reactive power control and its association with terminal voltage regulation. Sinusoidal Interior Magnet Machine (IPM) Unlike an SPM in an interior or busied magnet synchronous machine (IPM) the magnets are mounted inside the rotor. Although a number of geometries are possible, a typical configuration is shown in fig.1The stator has the usual three phase sinusoidal winding. The difference in the geometry gives the following characteristics to the IPM machine

i) The machine is more robust, permitting a much higher speed of operation.

ii) The effective air gap in the $d^{e}$ axis is larger than that in the $\mathrm{q}^{\mathrm{e}}$ axis, which means the machine salient pole with $\mathrm{Ldm}<$ lqm (unlike a standard wound field synchronous machine) and

iii) With the effective air gap being low, the armature reaction effect becomes dominant.

The steady state analysis of a sinusoidal PM machine with an equivalent circuit and phasor diagram remains the same as a wound field machine except that equivalent field current, it should be considered constant, that is the flow linkage $\psi \mathrm{f}=$ $\mathrm{Lm}, \mathrm{I}_{\mathrm{f}}=$ constant. The synchronously rotating frame transient equivalent circuit is also hold true here, expect the machine may not have any damper windings.

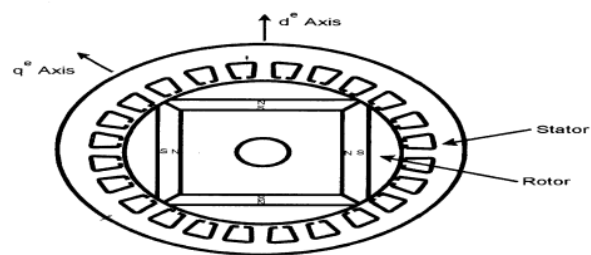

Fig.1 Cross Section of Interior Permanent Magnet Sinusoidal Machine (IPM)

\section{MATHEMATICAL MODEL OF PMSM}

a) PMSM is an important category of the electric machines, in which the rotor magnetization is created by permanent magnets attached to the rotor. Many mathematical models have been proposed for different applications, such as the $a b c$ model and the two axis $d q$-model. Due to the simplicity of the two axis $d q$-model, it becomes the most widely used model in PMSM engineering controller design. The $d q$-model offers significant convenience for control system design by transforming stationary symmetrical AC variables to DC ones in a rotating reference frame. Based on the $d q$ reference frame theory, the mathematical model of the PMSM can be expressed as in PMSM equations \& its motion. Model.

The two axes PMSM stator windings can be considered to have equal turn per phase. The rotor flux can be assumed to be concentrated along the $\mathrm{d}$ axis while there is zero flux along the $\mathrm{q}$ axis, an assumption similarly made in the derivation of indirect vector controlled induction motor drives. Also, rotor flux is assumed to be constant at a given operating point.
There is no need to include the rotor voltage equation as in the induction motor since there is no external source connected to the rotor magnet and variation in the rotor flux with respect to time is negligible. The stator equations of the induction machine in the rotor reference frames using flux linkages are taken to derive the model of the PMSM. The rotor reference frame is chosen because the position of the rotor magnets determine independently of the stator voltages and currents, the instantaneous induced emfs and subsequently the stator currents and torque of the machine. In Induction motor, the rotor fluxes are not independent variables, they are influenced by the stator voltage and currents and that is why any frame of reference is suitable for the dynamic modeling of the induction machine.

\section{(a) PMSM equations \& its motion Model}

The stator flux linkage vector and rotor flux linkage of PMSM can be drawn in the rotor flux (dq), stator flux (xy), and stationary (DQ) frames as shown in figure 2

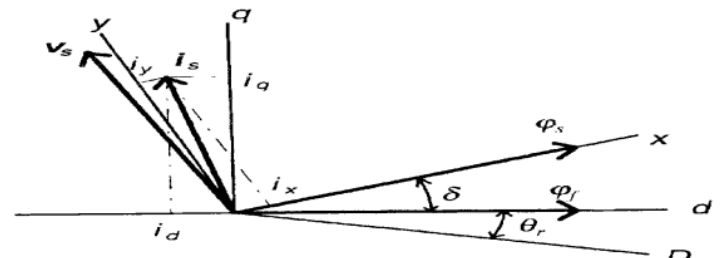

Fig.2 The Stator \& Rotor Flux Linkages in different reference frames

The characteristics of the salient pole machine differ from those of a nonsalient pole machine because of the non uniform air gap reluctances in the $\mathrm{d}^{\mathrm{e}}$ and $\mathrm{q}^{\mathrm{e}}$ axes. The resulting asymmetry in the direct and quadrature axes magnetizing reactance's causes the corresponding synchronous reactance's to be unsymmetrical (i.e., $\mathrm{X}_{\mathrm{ds}} \neq \mathrm{X}_{\mathrm{qs}}$ ). Figure 5(a) \&5(b) shows phasor diagrams of a salient pole machine for the motoring and generating modes, and also includes flux linkage. Again, for simplicity, the stator resistance has been dropped. The excitation or speed emf $V_{f}$ is shown aligned with the $\mathrm{q}_{\mathrm{e}}$ axes, whereas $\psi_{\mathrm{f}}$ is aligned with the $\mathrm{d}^{\mathrm{e}}$ axes. The phase voltage $V_{s}$ and phase current $I_{s}$ are resolved into corresponding $\mathrm{d}^{\mathrm{e}}$ and $\mathrm{q}^{\mathrm{e}}$ components, and a voltage phasor diagram is drawn with the corresponding reactive drops. In the phasor diagram, the armature reaction flux $\psi_{\mathrm{a}}$ aids the field flux to result in the stator flux $\psi_{\mathrm{s}}$ as shown. The motoring mode phasor diagram, which is drawn for lagging power factor, $\psi_{\mathrm{s}}>\psi_{\mathrm{f}}$, whereas in the generating mode, $\psi_{\mathrm{s}}<\psi_{\mathrm{f}}$, because it is operating at leading power factor. Note that $\mathrm{d}^{\mathrm{e}}-\mathrm{q}^{\mathrm{e}}$ axes phasor diagrams can also be drawn for a nonsalient pole machine where $\mathrm{X}_{\mathrm{ds}}=\mathrm{X}_{\mathrm{qs}}$.

From the phasor diagram, fig. 3 we can write

$\mathrm{I}_{\mathrm{s}} \cos \phi=\mathrm{I}_{\mathrm{qs}} \cos \delta-\mathrm{I}_{\mathrm{ds}} \sin \delta$

The figure can also be a vector diagram if all the rms phasors are multiplied by the factor $\sqrt{2}$, as mentioned before.

The power input to the machine is

$\mathrm{P}_{\mathrm{i}}=3 \mathrm{~V}_{\mathrm{s}} \mathrm{I}_{\mathrm{s}} \cos \phi$ 
Substituting equation (1) in (2), the input power $P_{i}$ can be given as

$\mathrm{P}_{\mathrm{i}}=3 \mathrm{~V}_{\mathrm{s}}\left(\mathrm{I}_{\mathrm{qs}} \cos \delta-\mathrm{I}_{\mathrm{ds}} \sin \delta\right)$

Again, from the phasor diagram we can write

$\mathrm{I}_{\mathrm{ds}}=\mathrm{V}_{\mathrm{s}} \cos \delta-\mathrm{V}_{\mathrm{f}} / \mathrm{X}_{\mathrm{ds}}$

$\mathrm{I}_{\mathrm{ds}}=\mathrm{V}_{\mathrm{s}} \sin \delta / \mathrm{X}_{\mathrm{qs}}$

Substituting equations (4) $-(5)$ in (3) yields

$P_{i}=3 \frac{V_{s} V_{f}}{X_{d s}} \sin \delta+3 V_{s}^{2} \frac{\left(X_{d s}-X_{q s}\right)}{2 X_{d s} X_{q s}} \sin 2 \delta$

or

$T_{e}=3\left(\frac{p}{2}\right) \frac{1}{\omega_{e}}\left(\frac{V_{s} V_{f}}{X_{d s}} \sin \delta+V_{s}^{2} \frac{\left(X_{d s}-X_{q s}\right)}{2 X_{d s} X_{q s}} \sin 2 \delta\right)$

$T_{e}=3\left(\frac{p}{2}\right)\left(\frac{\psi_{s} \psi_{f}}{L_{d s}} \sin \delta+\psi_{s}^{2} \frac{\left(L_{d s}-L_{q s}\right)}{2 L_{d s} L_{q s}} \sin 2 \delta\right)_{-}$

The torque developed in an IPM machine has two components: (1) the component due to field flux, and (2) the reluctance torque components. The general torque expression of a salient pole machine can be given by

$T_{e}=\frac{3}{2}\left(\frac{p}{2}\right)\left(\frac{\psi_{s} \psi_{f}}{L_{d s}} \sin \delta+\psi_{s}^{2} \frac{\left(L_{d s}-L_{q s}\right)}{2 L_{d s} L_{q s}} \sin 2 \delta\right)$

or

$T_{e}=\frac{3}{2}\left(\frac{p}{2}\right)\left(\psi_{d s} i_{q s}-\psi_{q s} i_{d s}\right)$

where $\mathrm{P}=$ number of poles, $\psi_{\mathrm{ds}}=\psi_{\mathrm{f}}+\mathrm{L}_{\mathrm{ds}} \mathrm{i}_{\mathrm{ds}}, \psi_{\mathrm{qs}}=\mathrm{L}_{\mathrm{qs}} \mathrm{i}_{\mathrm{qs}}$, and $\psi_{s}=\sqrt{\psi_{d s}^{2}+\psi_{q s}^{2}}$. Note that equation (8) is same as equation (9), except the rms phasor have been replaced by corresponding peak values $\left(\psi_{f}=\sqrt{2} \psi_{f}\right.$ and $\left.\psi_{s}=\sqrt{2} \psi_{s}\right)$. Substituting $\psi_{\mathrm{ds}}$ and $\psi_{\mathrm{qs}}$ equations in Equation , we get

$T_{e}=\frac{3}{2}\left(\frac{P}{2}\right)\left[\psi_{f} i_{q s}+\left(L_{d s}-L_{q s}\right) i_{d s} i_{q s}\right]$

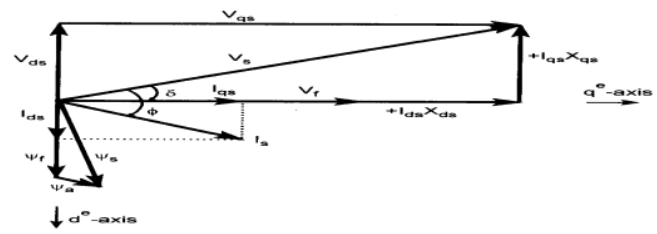

Fig.3a Phasor Diagram of Salient pole machine - Motoring mode

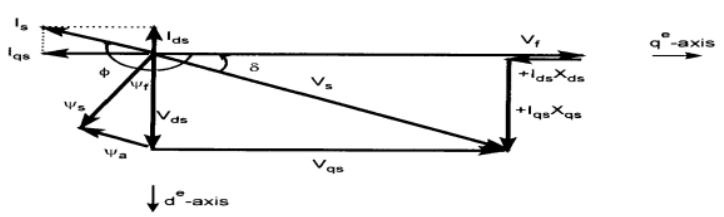

Fig.3b Phasor Diagram of Salient pole Machine- Generating Mode

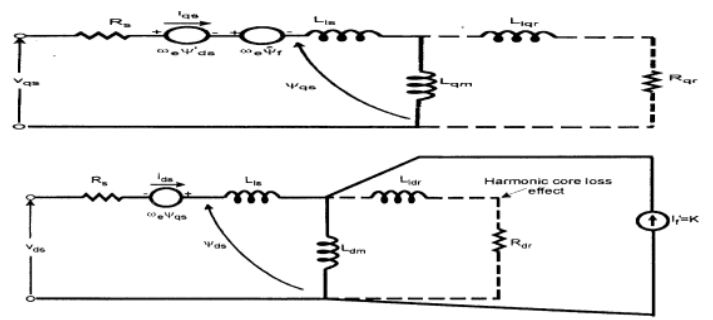

Fig .4 synchronously rotating frame (d-q) equivalent circuit of IPM machine.

The steady-state analysis of a sinusoidal PM machine with an equivalent circuit and phasor diagram remains the same as a wound field machine except that the equivalent field current $I_{f}$ should be considered constant, that is, the flux linkage $\psi_{\mathrm{f}}=\mathrm{L}_{\mathrm{m}} \mathrm{I}_{\mathrm{f}}=$ constant. The synchronously rotating frame transient equivalent circuits, shown in figure 4, also hold true here, except the machine may not have any damper winding. Figure 5 shows the equivalent circuit where the finite core loss is represented by the dotted damper windings. ignoring the core loss.

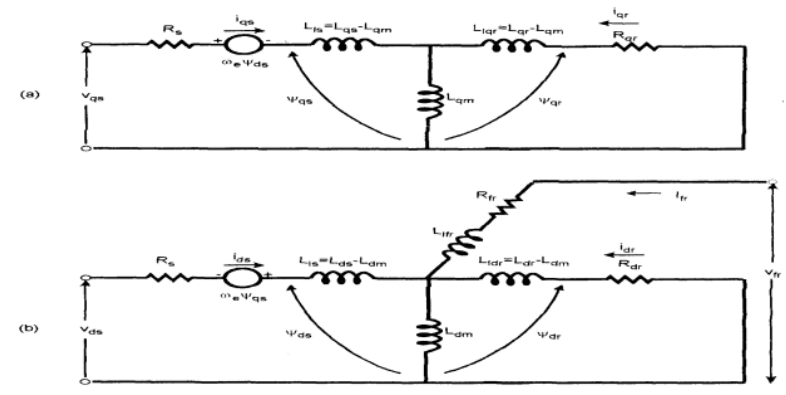

Fig.5 equivalent circuit of synchronous machine for $\mathrm{q} \& \mathrm{~d}$ axis circuit.

The circuit equations can be written as

$$
\begin{gathered}
v_{q s}=R_{s} i_{q s}+\omega_{e} \psi_{d s}+\omega_{e} \psi_{f}+\frac{d}{d t} \psi_{q s} \\
v_{d s}=R_{s} i_{q s}-\omega_{e} \psi_{d s}+\omega_{e} \psi_{q s}+\frac{d}{d t} \psi_{d s}
\end{gathered}
$$

Where,

$\psi_{\mathrm{f}}=\mathrm{L}_{\mathrm{dm}} \mathrm{I}_{\mathrm{f}}$

$\psi_{\mathrm{ds}}=\mathrm{i}_{\mathrm{ds}}\left(\mathrm{L}_{\mathrm{ls}}+\mathrm{L}_{\mathrm{dm}}\right)=\mathrm{i}_{\mathrm{ds}} \mathrm{L}_{\mathrm{ds}}$

$\psi_{\mathrm{ds}}=\psi_{\mathrm{f}}+\psi_{\mathrm{ds}}$

$\psi_{\mathrm{qs}}=\mathrm{i}_{\mathrm{qs}}\left(\mathrm{L}_{\mathrm{ls}}+\mathrm{L}_{\mathrm{qm}}\right)=\mathrm{i}_{\mathrm{qs}} \mathrm{L}_{\mathrm{qs}}$

and the torque equation is 
Substituting equations (14)- (17) in (12), (13) and (18) and simplifying we can write

$$
\begin{aligned}
& \left.\frac{d i_{q s}}{d t}=\frac{\omega_{b}}{X_{q s}} \mid v_{q s}-R_{s} i_{q s}-\frac{\omega_{e}}{\omega_{b}} X_{d s} i_{d s}-\frac{\omega_{e}}{\omega_{b}} V_{f}\right] \\
& \frac{d i_{d s}}{d t}=\frac{\omega_{b}}{X_{d s}}\left[v_{d s}-R_{s} i_{d s}-\frac{\omega_{e}}{\omega_{b}} X_{q s} i_{q s}\right] \\
& T_{e}=\frac{3 P}{4 \omega_{b}}\left[\left(F^{\prime}{ }_{d s}+V_{f}\right) i_{q s}-F_{q s} i_{d s}\right]
\end{aligned}
$$

Where $\mathrm{V}_{\mathrm{f}}=\omega_{\mathrm{b}} \psi_{\mathrm{f}}, \mathrm{X}_{\mathrm{qs}}=\omega_{\mathrm{b}} \mathrm{L}_{\mathrm{qs}}, \mathrm{X}_{\mathrm{ds}}=\omega_{\mathrm{b}} \mathrm{L}_{\mathrm{ds}}, \mathrm{F}_{\mathrm{ds}}^{\prime}=\omega_{\mathrm{b}} \psi_{\mathrm{ds}}, \mathrm{F}_{\mathrm{qs}}$ $=\omega_{\mathrm{b}} \psi_{\mathrm{gs}}$, and $\omega_{\mathrm{b}}=$ base frequency. These equations, which are valid for IPM as well as SPM (except $\mathrm{L}_{\mathrm{dm}}=\mathrm{L}_{\mathrm{qm}}$ ), can be used for computer simulation study.

Again for steady-state operation of the machine, the time derivative components of Equation (12) and (13) are zero.

\section{b) Torque Analysis of PMSM}

Permanent Magnet synchronous motors (PMSM's) are used in many applications that require rapid torque response and high performance operation. The torque in PMSM's is usually controlled by controlling the armature current based on the fact that the electromagnetic torque is proportional to the armature current. For high performance the current control is normally executed in the rotor $\mathrm{dq}$ reference frame that rotates with the synchronous speed. In this frame, the armature inductances and magnet flux linkage are constant if the back electromotive force (EMF) and variation of inductances are sinusoidal. In addition to the influence of the harmonic terms in inductances and back EMF, saturation in flux, and temperature effect on the magnet, the torque response under current control is limited by the time constant of the armature windings.

Motor Equation in the stator flux reference frame:

The stator flux linkage vector $\varphi_{\mathrm{s}}$ and rotor (magnet) flux linkage vector $\varphi_{\mathrm{f}}$ can be drawn in the rotor flux (dq), stator flux (xy) and stationary (dq) reference frames, as in fig.2

The angle between the stator and rotor flux linkages $\delta$ is the load angle when the stator resistance is neglected. In the steady state, $\delta$ is constant corresponding to a load torque, and both stator and rotor flux rotate at the synchronous speed. In transient operation, $\delta$ varies and the stator and rotor flux rotate at different speeds. Since the electrical time constant is normally much smaller than the mechanical time constant, the rotating speed of stator flux, with respect to the rotor flux, can be easily changed. It is shown in this section that the increase of torque can be controlling the change of $\delta$ or the rotating speed of the stator flux.

The well-known stator flux linkage, voltage, and electromagnetic torque equations in the dq reference frame are as follows:

$$
\begin{array}{ll}
\varphi d & =\mathrm{L}_{\mathrm{dd}}^{\mathrm{i}}+\varphi_{\mathrm{f}} \\
\varphi \mathrm{d} & =\mathrm{L}_{\mathrm{q}}^{\mathrm{i}} \\
\mathrm{v}_{\mathrm{d}} & =\mathrm{R}_{\mathrm{sd}}^{\mathrm{i}}+p \varphi d-\omega_{\mathrm{r}} \varphi \mathrm{q}
\end{array}
$$

$$
\begin{array}{ll}
\mathrm{v}_{\mathrm{d}} & =\mathrm{R}_{\mathrm{sq}}^{\mathrm{i}}+\mathrm{p} \varphi \mathrm{q}-\omega_{\mathrm{r}} \varphi \mathrm{d} \\
\mathrm{T} & =3 / 2 \mathrm{p}\left(\varphi_{\mathrm{d} q}-\varphi_{\mathrm{q} d}{ }_{\mathrm{i}}\right)
\end{array}
$$

Where $\varphi_{\mathrm{f}}, \mathrm{L}_{\mathrm{d}}$, and $\mathrm{L}_{\mathrm{q}}$ are the armature (or stator) back EMF constant and inductances, respectively, when the back EMF and the variation of the stator inductances are sinusoidal. Otherwise, these are the fundamental quantities of these variables. With the transformation in (25) and (26), (22)-(24) can be transformed to the xy reference frame:

$\left[\begin{array}{l}F_{x} \\ F_{y}\end{array}\right]=\left[\begin{array}{ll}\cos \delta & \sin \delta \\ -\sin \delta \cos \delta\end{array}\right]\left[\begin{array}{l}F_{d} \\ F_{q}\end{array}\right]$.

The inverse transformation is

$\left[\begin{array}{l}F_{a} \\ F_{a}\end{array}\right]=\left[\begin{array}{l}\cos \delta-\sin \delta \\ \sin \delta \cos \delta\end{array}\right]\left[\begin{array}{l}F_{x} \\ F_{y}\end{array}\right]$

Where F represents the voltage, current, and flux linkage.

A) The torque Equation in xy Reference Frame

From fig.2, it can be found that

$\sin \delta=\frac{\varphi_{q}}{\left|\varphi_{s}\right|}$
$\cos \delta=\frac{\varphi_{d}}{\left|\varphi_{s}\right|}$

Where $\left|\varphi_{\mathrm{s}}\right|$ represents the amplitude of the stator flux linkage. Substituting (26) and (27) for current into (23) gives

$$
\begin{aligned}
& T=\frac{3}{2} p\left[\varphi_{d}\left(t_{x} \sin \delta+t_{y} \cos \delta\right)-\varphi_{d}\left(t_{x} \cos \delta-t_{y} \sin \delta\right)\right] \\
& =\frac{3}{2} p\left[i_{x} \frac{\varphi_{d} \varphi_{q}}{\left|\varphi_{s}\right|}+i_{y} \frac{\varphi_{d}^{2}}{\left|\varphi_{s}\right|}-i_{x} \frac{\varphi_{d} \varphi_{q}}{\left|\varphi_{s}\right|}+i_{y} \frac{\varphi_{d}^{2}}{\left|\varphi_{s}\right|}\right]=\frac{3}{2} p\left|\varphi_{s}\right| i_{y}--(28)
\end{aligned}
$$

Equation (28) means that the torque is directly proportional to the $y$-axis component of the stator current if the amplitude of the stator flux linkage is constant.

B) The flux linkage Equation in the xy reference frame Equation can be rewritten into matrix from as follows:

$\left[\begin{array}{l}\varphi_{d} \\ \varphi_{q}\end{array}\right]=\left[\begin{array}{lll}L_{d} & 0 & \rceil\left\lceil i_{d}\right. \\ 0 & L_{q}\end{array}\right]\left\lfloor i_{q}\right]+\left[\begin{array}{l}\varphi_{f} \\ 0\end{array}\right]$

Substituting (26) into (29) gives

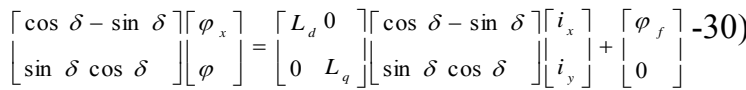

Premultiplying (30) with

$\left[\begin{array}{l}\cos \delta-\sin \delta \\ \sin \delta \cos \delta\end{array}\right]^{-1}=\left[\begin{array}{cc}\cos \delta & \sin \delta \\ -\sin \delta \cos \delta\end{array}\right]$

gives (32),

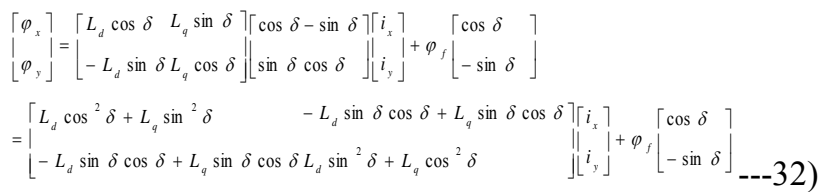

PMSM'a with Uniform Airgap: for this type of PMSM, $\mathrm{L}_{\mathrm{d}}=\mathrm{L}_{\mathrm{q}}=$ $\mathrm{L}_{\mathrm{s}}$ can be simplified as in (12) 
$\left[\begin{array}{l}\varphi_{x} \\ \varphi^{\prime}\end{array}\right]=\left[\begin{array}{ll}L_{s} 0 \\ 0 & L_{s}\end{array}\right]\left[\begin{array}{l}i_{x} \\ i_{y}\end{array}\right]+\varphi_{f}\left[\begin{array}{l}\cos \delta \\ -\sin \delta\end{array}\right]$

or

$\varphi_{\mathrm{x}}=\mathrm{L}_{\mathrm{s} \mathrm{x}}^{\mathrm{i}}+\varphi_{\mathrm{f}} \cos \delta$

$\varphi_{\mathrm{y}}=\mathrm{L}_{\mathrm{s} \mathrm{s}}^{\mathrm{i}}-\varphi_{\mathrm{f}} \sin \delta$

$\varphi_{\mathrm{y}}$ is zero since the $\mathrm{x}$ - axis is fixed at the stator flux linkage.

Then, $i_{\mathrm{y}}$ can be solved from the second equation of (34)

$\mathrm{i}_{\mathrm{y}}=1 / \mathrm{L}_{\mathrm{s}} \times \varphi_{\mathrm{f}} \sin \delta$

Substituting (35) into torque (28) gives

$T=\frac{3}{2} \frac{1}{L_{s}} p\left|\varphi_{s}\right| \varphi_{f}\left|\sin \delta=\frac{3}{2} \frac{1}{L_{s}} p\right| \varphi_{s}\left|\varphi_{f}\right| \sin \delta t^{-36)}$

Where $\delta$ is the angular velocity of the stator flux linkage relative to magnet flux linkage.

Equation (36) implies that the torque increases with the increase in $\delta$ if the amplitude of the stator flux linkage is kept constant and $\delta$ is controlled within the range of $-\pi / 2-\pi / 2$.

The maximum torque occurs when $\delta$ is $\pi / 2$.

$\delta$ is considered to be a step change corresponding to a change of voltage vector. Then, the derivative of (36) becomes

$\left.\frac{d T}{d t}\right|_{t=0}=\frac{3}{2} p \frac{\left|\varphi_{s}\right| \varphi_{f}}{L_{s}} \delta \cos \delta$

The right-hand side of (37) is always positive if $\delta$ is positive if $\delta$ is within the range of $-\pi / 2-\pi 2$. This equation implies that the increase of torque is proportional to the increase of the angle $\delta$, which is the angle between the stator and magnet flux linkage. In other words, the stator flux linkage should be controlled in such a way that the amplitude is kept constant and the rotating speed is controlled as fast as possible to obtain the maximum change in actual torque.

PMSMs with pole saliency: for a PMSM with pole saliency, that is, $\mathrm{L}_{\mathrm{d}} \neq \mathrm{L}_{\mathrm{q}}$, the torque equation in terms of stator flux linkage and angle $\delta$ can be obtained by solving $i_{\mathrm{x}}$ from (33), with $\varphi_{\mathrm{y}}=0$ :

$i_{x}=\frac{2 \varphi_{f} \sin \delta-\left[\left(L_{d}+L_{q}\right)+\left(L_{d}-L_{q}\right) \cos 2 \delta\right.}{\left(L_{q}-L_{d}\right) \sin 2 \delta} i_{y}$

Substituting (38) into the first equation in (32), one obtains

$i_{y}=\frac{1}{2 L_{d} L_{q}}\left[2 \varphi_{f} L_{q} \sin \delta-\left|\varphi_{s}\right|\left(L_{q}-L_{d}\right) \sin 2 \delta^{-39)}\right.$

Then, the torque equation is as follows:

$T=\frac{3 p\left|\varphi_{s}\right|}{4 L_{d} L_{q}}\left[2 \varphi_{f} L_{q} \sin \delta-\left|\varphi_{s}\right|\left(L_{q}-L_{d}\right) \sin 2 \delta\right]$

Equation (40) consists of two terms. The first is the excitation torque, which is produced by the permanent magnet flux, and the second term is the reluctance torque. For each stator flux linkage, there exists the maximum in this equation. It will not be discussed how to control the amplitude of stator flux linkage and load angle to get maximum torque. However, it is necessary to discuss the relationship between the amplitude of stator flux linkage and the derivative of the torque Therefore, for a PMSM with pole saliency, the amplitude of the stator flux linkage should be changer, with the change of actual torque even for constant torque operation.

The derivative of torque in (41) is as shown in (42), with constant stator flux and $\mathrm{d} \delta / \mathrm{dt}$ :

$\frac{d T}{d t}=\frac{3 p\left|\varphi_{s}\right|}{4 L_{d} L_{q}}\left[2 \varphi_{f} L_{q} \delta \cos \delta-2\left|\varphi_{s}\right|\left(L_{q}-L_{d}\right) \delta \cos 2 \delta\right]$

At $\mathrm{t}=0$ :

$\left.\frac{d T}{d t}\right|_{t=0}=\frac{3 p\left|\varphi_{s}\right|}{2 L_{d} L_{q}}\left[\varphi_{f} L_{q} \delta-\left|\varphi_{s}\right|\left(L_{q}-L_{d}\right) \delta\right]$

The condition for $\mathrm{dT} / \mathrm{dt}$ for positive $\mathrm{d} \delta / \mathrm{dt}$ is

$\left|\varphi_{s}\right|<\frac{L_{q}}{L_{q}-L_{d}} \varphi_{f}$

The Primary voltage vector $\mathrm{v}_{\mathrm{s}}$ is defined by the following equation $v_{s}=\frac{2}{3}\left(v_{a}+v_{b} e^{i(2 / 3) \pi}+v_{c} e^{(4 / 3) \pi}\right.$

The amplitude of the stator flux linkage should be chosen according to (44) if fast dynamic response is desired. Otherwise, the should be varied with the change of actual torque if the linearity is more important. It should also be kept in mind that for the same torque, a higher stator current is needed when the amplitude of the stator flux linkage is lower.[4]

\section{METHODOLOGY}

\section{a) PMSM drive using SVPWM}

Space Vector PWM Inverter refers to a sequential switching of six switches (1GBT transistors) of a three-phase three leg bridge inverter which generate less harmonic distortion in the output voltages and currents, which provides more efficient use of supply voltage as compared to sinusoidal modulation technique. The circuit model of a three-phase voltage source PWM inverter is shown in Fig.6. SI to S6 are the six power switches, when any upper switch is on ( $\mathrm{a}, \mathrm{b}$ or $\mathrm{c}$ is 1$)$, the corresponding lower switches is turned off, ( $a^{\prime}, b^{\prime}$ or $c^{\prime}$ is 0 ). Therefore, the on and off states of the upper switches S1, S3 and S5 can be used to detuning the output voltage $[3,5,6]$.

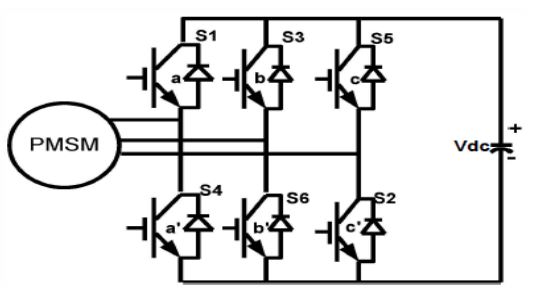

Fig.6 Three phase voltage source PWM Inverter with PMSM

The relationship between the switching variable vector $[a, b, c]^{\wedge} t$ and the line-to-line voltage vector $\left[\mathrm{Vab} \mathrm{Vbc} \mathrm{Vc}^{\wedge} \mathrm{t}\right.$ is given by

$$
\left[\begin{array}{l}
V_{\mathrm{ab}} \\
\mathrm{V}_{\mathrm{bc}} \\
\mathrm{V}_{\mathrm{ca}}
\end{array}\right]=\mathrm{V}_{\mathrm{dc}}\left[\begin{array}{ccc}
1 & -1 & 0 \\
0 & 1 & -1 \\
-1 & 0 & 1
\end{array}\right]\left[\begin{array}{l}
\mathrm{a} \\
\mathrm{b} \\
\mathrm{c}
\end{array}\right]
$$


There are eight possible combinations of on and off patterns for the three upper power switches, as shown in table I [9].

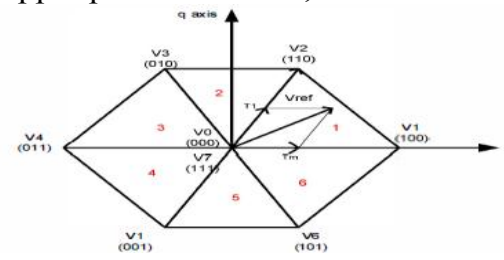

Fig.7 Basic switching voltage vectors and sectors

Fig.7 shows the switching voltage vectors and sectors where $\mathrm{Tl}$ and Tm refers to the operation times of two adjacent nonzero voltage space vectors in the same zone [7]. Both Vo (000) and V7 (111) are called the zero voltage space vector, and the other six vectors are called the effective vector with a magnitude of $2 \mathrm{Vdc} / 3$. Based on the principle of SVPWM, the simulink model of SVPWM is shown in Fig. 8 which primarily include the sector judgment model, operation, time calculation model for fundamental vectors, calculation model of switching time, and generation model of SVPWM waveforms $[7,8,9]$.

Table 1 switching vectors and line voltages

\begin{tabular}{|c|c|c|c|c|c|c|}
\hline Voltage & \multicolumn{3}{|c|}{ Switching Vectors } & \multicolumn{3}{c|}{ Line to line voltage } \\
\cline { 2 - 7 } & $\boldsymbol{a}$ & $\boldsymbol{b}$ & $\boldsymbol{c}$ & $\boldsymbol{V} \boldsymbol{a} \boldsymbol{b}$ & $\boldsymbol{V} \boldsymbol{b c}$ & $\boldsymbol{V} \boldsymbol{c a}$ \\
\hline $\mathrm{V}_{0}$ & 0 & 0 & 0 & 0 & 0 & 0 \\
\hline $\mathrm{V}_{1}$ & 1 & 0 & 0 & 1 & 0 & -1 \\
\hline $\mathrm{V}_{2}$ & 1 & 1 & 0 & 0 & 1 & -1 \\
\hline $\mathrm{V}_{3}$ & 0 & 1 & 0 & -1 & 1 & 0 \\
\hline $\mathrm{V}_{4}$ & 0 & 1 & 1 & -1 & 0 & 1 \\
\hline $\mathrm{V}_{5}$ & 0 & 0 & 1 & 0 & -1 & 1 \\
\hline $\mathrm{V}_{6}$ & 1 & 0 & 1 & 1 & -1 & 0 \\
\hline $\mathrm{V}_{7}$ & 1 & 1 & 1 & 0 & 0 & 0 \\
\hline
\end{tabular}

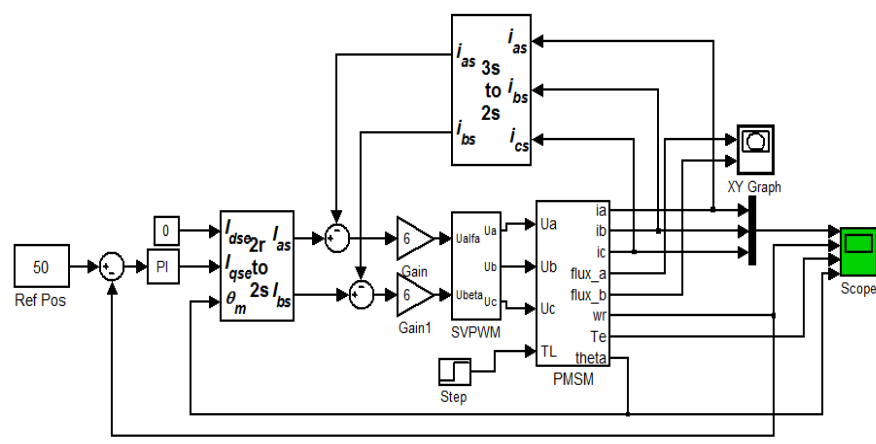

Fig.8 SVPWM PMSM Drive Simulink Model

\section{b) PMSM drive using dual inverter}

Fig. 9 shows winding of motor for dual inverter drive. If dual inverter topology is applied to the concentrated wound structure as shown in Fig. , parameters of each divided motors such as inductance, $\mathrm{Ld}$ and $\mathrm{Lq}$, resistance, Rs, flux linkage made by permanent magnet, $\lambda f$, are divided equally with the stator split ratio, $\mathrm{D}$, in the ideal case where side effects are neglected. A PMSM with the concentrated windings, whose $d-$ and qaxis inductances, stator resistance and back-EMF constant are Ld, Lq, Rs, divided with N1 vs. N2, and then the split ratio can be defined and $\lambda \mathrm{f}$, respectively, is considered. If the stator is

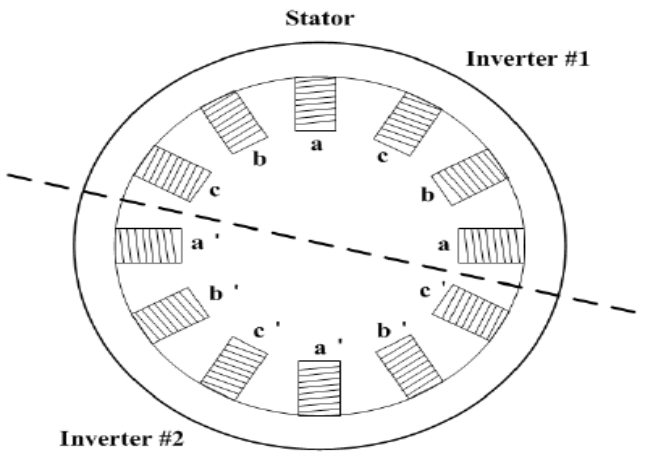

Fig.9 PMSM drive using Dual Inverter

as $\mathrm{D}$, which is $\mathrm{N} 1 /(\mathrm{N} 1+\mathrm{N} 2)$. The parameters of one split motor \#1 are D $\cdot \mathrm{Ld}, \mathrm{D} \cdot \mathrm{Lq}, \mathrm{D} \cdot \mathrm{Rs}$, and D $\cdot \lambda \mathrm{f}$. And those of the other motor \#2 are (1-D) $\cdot \mathrm{Ld},(1-\mathrm{D}) \cdot \mathrm{Lq},(1-\mathrm{D}) \cdot \mathrm{Rs}$, and $(1-\mathrm{D}) \cdot \lambda \mathrm{f}$. In this paper, it is considered that inverter \#1 feeds only the split motor $\# 1$, and inverter \#2 feeds only the other split motor \#2. The control of dual inverter system is similar with parallel drive of individual two motors. In the case of dual inverter system, it requires smaller $\mathrm{d}$ axis current than that of the single drive system because back EMF constant of split motor is lower than that of the non-split motor. Therefore, it is possible to control the given motor at the higher speed. And this current reduction gives advantages in minimizing the copper and inverter losses. The specific calculation of loss and operation range is presented in this paper. In the split, the concentrated winding motor as shown in Fig.10 is more decisive than the distributed winding one for dual inverter drive because the concentrated winding has lower shear effects. Since the inductances of the concentrated winding motor are reduced according to the inverse of $\mathrm{D}$, not $\mathrm{D}^{\wedge} 2$, the d-axis current can be reduced according to the ratio. Series split motor is also used in the accident case because one of inverter can drive the entire motor as in multi-phase drive.

Accordingly dual inverter drive provides safer operation than that of single inverter drive and this characteristic is suitable for high safety integrity applications such as EV and electric railways. However in accident case, it cannot generate sufficient torque and efficiency also falls since flux linkage through the paths where the inverter in the accident feeds makes core losses. 


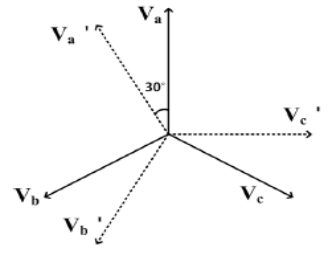

Fig.10(a)

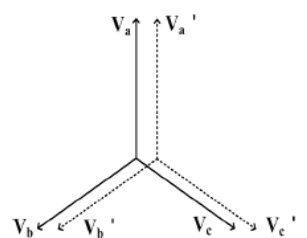

Fig.10(b)
Multi-phase inverter driven motor topology which studied before it can be classified into two groups as shown in Fig. 11 It is the case of 6-phase motor drive system. This system consists of two 3-phase inverters which have $30^{\circ}$ angle difference between two inverters. The 6-phase inverter has advantages in low torque ripple and the resultant voltage ripple of DC capacitor. However, 6-phase motor needs additional design factors

and has higher electric frequency for the operations because it has lower number of poles than that of the dual 3-phase drive system as shown in Fig.10(a). The dual 3-phase inverter drive system has lower electric frequency and design merit because it needs no change in the design. Of course it requires selection or split for optimal efficiency control.

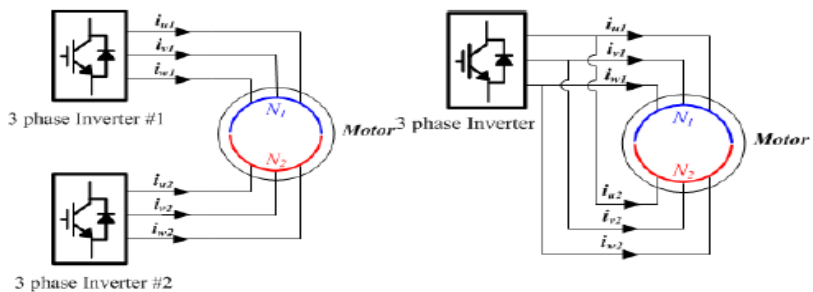

Fig.11 Block diagram of Dual inverter system controller.

It is also possible to drive the split motor with single inverter as in Fig.10(b). Where the motor is divided equally, i.e. $\mathrm{D}=$ 0.5 , the characteristics are same for both split motor. If system is constructed as in Fig.10 (b), only one inverter is necessary for the same operations of Fig.10(a). However, this structure needs high current in switching device and if parameters of two split parts are different with any reasons, large torque ripples are generated and efficiency drops. There can be parameter difference coming from motor manufacturing. Thus, the independent feeding structure as in Fig. 11 is recommended.

Fig. 11 shows block diagram of dual inverter system controller. Each inverter is controlled by independent current controller and each current controller is controlled by one common speed controller or torque controller. Torque divider generates each torque reference from output of the speed controller. The field weakening controller also works independently of other current controller. A concentrated wound motor is used. Experiments and simulations are carried out with parameters in the table below and simulation results of the same are depicted in the figures in the end of this section. [6]

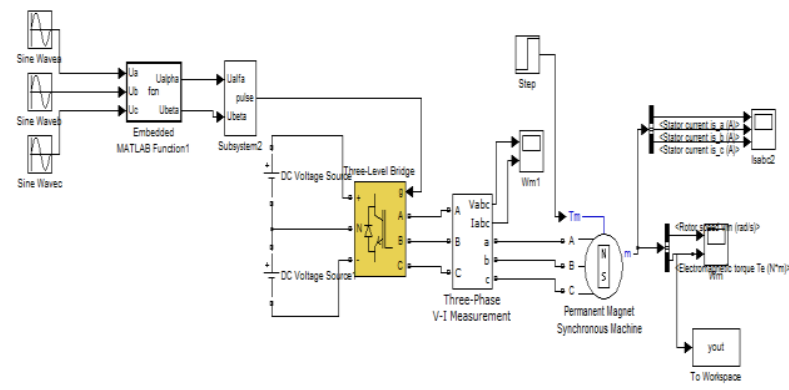

Fig.12 Dual Inverter PMSM Drive Simulink Model.

\section{SIMULATION RESULT AND ANALYSIS}

The simulink model of proposed DTC for PMSM drive based on SVPWM \&Dual Inverter is shown in Fig 8\&Fig.12 the Results are taken for specific value of PMSM parameters given in Table 2 The simulation result of proposed DTC for PMSM drive based on SVPWM is shown in fig. $13,14 \& 15$.

Table 2 Specification of PMSM

\begin{tabular}{|c|l|l|}
\hline Sr. No. & PMSM Parameter & Value \\
\hline 1. & Stator Resistance Rs & 2.875 \\
\hline 2. & d-axis Inductance Ld & $8.5 \times 10^{-3}$ \\
\hline 3. & q-axis Inductance Lq & $8.5 \times 10^{-3}$ \\
\hline 4. & Permanent Magnet Flux & 0.175 \\
\hline 5. & No of Poles & 4 \\
\hline
\end{tabular}

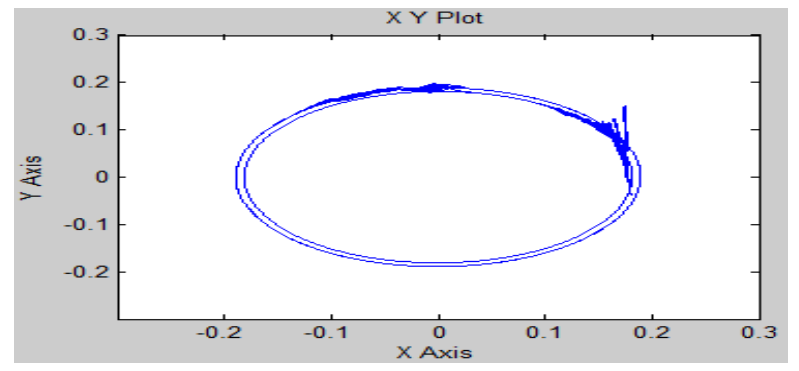

Fig.13 Flux Trajectory

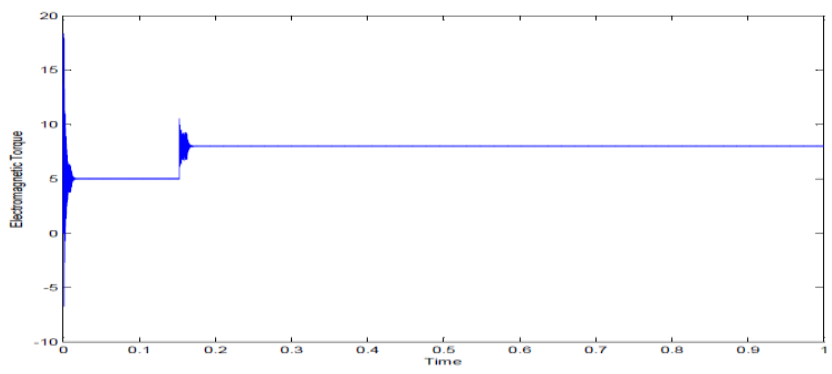


Fig.14 Performance of SVM-DTC of motor

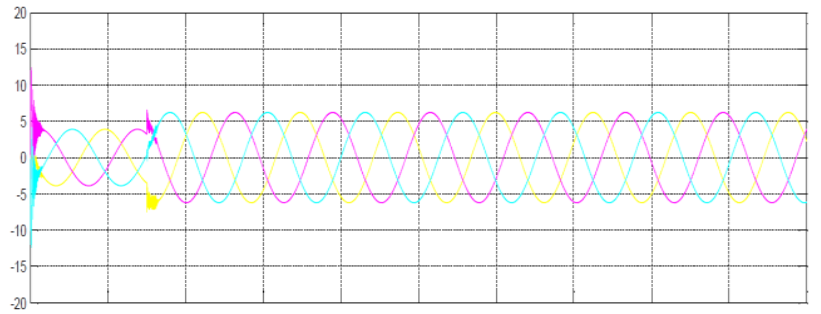

Fig.15 Three phase stator current waveform

Inference:

Rated Torque $=0.8 \mathrm{Nm}$

Torque ripple $(\%)=($ Peak to peak torque/ Average torque $) *$ 100

$=((18.36-10.55) / 800) * 100$

$=0.9762 \%$

As seen from torque response curve, at starting of PMSM, torque ripple is larger, because instantaneous rate of change of stator flux linkage is larger than that of rotor flux linkage. When the actual motor torque becomes less than the given value, the angle between the stator and rotor flux linkage increases, that leads torque growing fast; and vice versa, after a exact equilibrium state; the torque as well as speed settles very fast to final value. The three phase stator current is shown in fig 8, will remains same for all values of speed $(\mathrm{O}) \mathrm{r}=$ $600 \mathrm{rpm}$ and $900 \mathrm{rpm}$ ) only it changes with dynamic loading (value of load torque), it may increase or decrease with value, as in this case increasing with increase in load torque as applied at $0.1 \mathrm{sec}$. The stator current settles to a steady state value very fast within two cycles. The results are taken for specific value of PMSM parameters given in Table 3 The simulation result of proposed Dual Inverter is shown in fig. 16 .

Inference:

Rated Torque $=0.8 \mathrm{Nm}$

Torque ripple $(\%)=($ Peak to peak torque/ Average torque $) *$ 100

$=((0.61-0.0946) / 8) * 100$

$=6.442 \%$

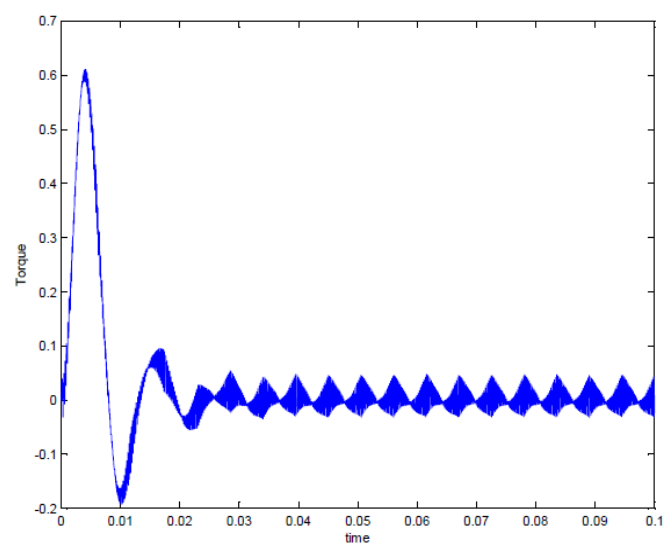

Fig.16 Performance of Dual inverter-DTC of motor

\section{CONCLUSION}

A new direct torque control techniques of PMSM in this paper. The theoretical analyses and simulation results indicates that SVPWM technique can reduce the flux linkage and torque ripple in a large extent and have a better dynamic and static performance as compare to dual inverter technique. So the SVM-DTC is feasible and more effective for automotive application. 


\section{REFERENCES}

[1]. Pragasen Pillay, Application Characteristics of Permanent Magnet Synchronous and Brushless DC Motors for Servo Drives. IEEE trans, Industry applications (27), 986-996 (Sept/Oct. 1991)

[2]. Teck-seng Low, Mohanned.A. Jabbar Permanent Magnet Motors for Brushless Operation IEEE trans. Industry application (26), 124-129(Jan/Feb 1990)

[3]. Lixin Tang, Limin Zhong, A novel direct torque control for interior permanent magnet synchronous machine drive with low ripple in toque and flux. IEEE trans on Industry applications 39(6) 17481756(2003)

[4]. Pragasen Pillay, Ramu Krishnan, "Modeling Simulation and Analysis of Permanent Magnet Motor Drives"Part 1: The Permanent Magnet Synchronous Drive.Part 2: The Brushless Motor Drive.IEEE trans. Industry Applications,25(2) 265279( March/April 1989)

[5]. M.N. Uddin and al., Performance of current controllers for IPMSM drive, in Proc. of the IEEE IAS Annual Meeting, (2), 1018-1025 (1999).

[6]. M Kadjoudj, R.Abdessemed, M E Benbouzid, C Ghennai,Current control of PMSM fed by two and three levels VSI. in Proc. of EPE/PEMC, Tuke (Slovakia). (7) 69-74(2000)

[7]. D Sun, F Weizhong, H Yikang, Study on the Direct Torque Control of Permanent Magnet Synchronous Motor Drives. IEEE/ ICEMS. 571-574(2001)

[8]. Xiaoting Ye, Tao Zhang, "Direct Torque Control of Permanent Magnet Synchronous Motor Using Space Vector Modulation", Proc. IEEE Chinese Control and Decision Conference 1450-1453 (2010)

[9]. Sanda Victorinne Paturca," Direct Torque Control of Permanent Magnet Synchronous Motor (PMSM) an approach by using Space Vector Modulation (SVM)", Proc. of the 6th WSEAS/IASME In Conf. on Electric Power Systems, High Voltages, Electric Machines, 16-18(2006)
[10]. LT Yaohua, Yu Qiang, Zhang Depeng, Guan Jiawu, Cai Hongmin , "Study on the use of zero voltage vectors in the PMSM DTC Systems", Proc. Of 30th Chinese control conf., 3559-3564 (2011).

[11]. C. Mademlis, I. Kioskeridis, N. Magaris, Optimal efficiency control strategy for interior permanent-magnet synchronous motor drives IEEE Trans. Energy Conversion., (19) 715-723 ( Dec. 2004). 12. T. Kwon, S. Sul, Novel antiwindup of a current regulator of a surfacemounted permanentmagnet motor for flux-weakening control IEEE Trans. Ind. Appl.(42) 1293-1300( Oct. 2006).

\section{Creative Commons Attribution License 4.0 (Attribution 4.0 International, CC BY 4.0)}

This article is published under the terms of the Creative Commons Attribution License 4.0 https://creativecommons.org/licenses/by/4.0/deed.en US 